\title{
Determination of DPPH Free Radical Scavenging Activity by RP-HPLC, Rapid Sensitive Method for the Screening of Berry Fruit Juice Freeze Dried Extract
}

\author{
Prasanna Kumara ${ }^{1 *}$, Sunil $\mathrm{K}^{1}$ and Arun Kumar $\mathbf{B}^{2}$ \\ ${ }^{1}$ Department of Chemistry, SSIT, Tumkur, Karnataka, India \\ ${ }^{2} R \& D$, The Himalaya Drug Company, Bengaluru, Karnataka, India \\ “Corresponding author: Prasanna Kumara, Department of Chemistry, SSIT, Tumkur, Karnataka, India, Tel: +91-0816 2200314; E-mail: prasannatp22@gmail.com
}

Received: August 27, 2018; Accepted: September 07, 2018; Published: September 17, 2018

Copyright: (c) 2018 Kumara P, et al. This is an open-access article distributed under the terms of the Creative Commons Attribution License, which permits unrestricted use, distribution, and reproduction in any medium, provided the original author and source are credited.

\begin{abstract}
USP official UV-VIS spectrophotometric method for the evaluation of antioxidant activity by scavenging the DPPH (1,1-diphenyl-2-picrylhydrazyl) free radical was not suitable to determine the antioxidant activity of Berry fruit juice freeze dried extract due to interferences from the matrix. Interference was also observed from the color pigments of the Berry fruit juice freeze dried extract. This has leads to the development of a specific analytical method for evaluation of the DPPH free radical scavenging activity of Berry fruit juice freeze dried extract. RP-HPLC method was developed on a Phenomenex Luna-C18 Column $(250 \mathrm{~mm} \times 4 \mathrm{~mm}, 5 \mu \mathrm{M})$ with mobile phase methanol and water mixed online in the ratio of $80: 20(\mathrm{v} / \mathrm{v})$, pumped at a flow rate of $1 \mathrm{~mL} / \mathrm{min}$. DPPH peaks were quantified at wavelength $517 \mathrm{~nm}$. Method was standardized using the anti-oxidant ascorbic acid. The $50 \%$ free radical scavenging activity $\left(\mathrm{IC}_{50}\right)$ determined by the novel HPLC method was correlating with the results obtained by USP UV-VIS spectrophotometric method. While the USP UV-VIS spectrophotometric method failed to estimate the free radical scavenging activity of Berry fruit juice freeze dried extract, whereas the developed HPLC method was specific, sensitive, robust, accurate and precise and rapid in the determination.
\end{abstract}

Keywords: Berry fruit juice; Freeze dried extract; Antioxidants; Reversed-phase HPLC; DPPH

\section{Introduction}

Antioxidants, particularly those which are capable to prevent the effects of free radicals in the human body and deterioration of food products are gaining interest among the industries and researchers. Especially, antioxidants from natural sources, rather than from synthetic sources [1] are gaining popularity. This increasing interest on using them is complimented by the increased use of analytical methods for the estimation of anti-oxidant efficiency of such substances [2,3].

One of the most popular methods is based on the use of a stable free radical diphenyl picrylhydrazyl (DPPH). The purpose of this paper is to examine the basis of this method and to further use the parameter "EC 50 " (equivalent concentration to give $50 \%$ effect) which is currently used in the experimental data interpretation.

It should be duly noted by the readers that the current paper neither correlates the results of the DPPH method to the anti-oxidant activity of the substance nor with the anti-oxidant efficiency and life-style enhancing capabilities of these substances in normal usage $[3,4]$. Users should use discretion while considering the anti-oxidant capabilities of the said materials.

The 1,1-diphenyl-2-picrylhydrazyl( $\alpha, \alpha$-diphenyl- $\beta$-picrylhydrazyl; DPPH:1) molecule is considered as a very stable free radical. The delocalization of spare electron over the molecule keeps the molecules from dimerization, while most other free radicals lack this unique feature. The delocalization also gives rise to a deep violet color, characterized by an absorption band in ethanol solution centered at about $517 \mathrm{~nm}$.

A solution of DPPH when mixed with a hydrogen donor substance, a reduced form (2) of the DPPH is formed, which can be indicated by the loss of violet color. A residual pale-yellow color from the picryl group can still be present in the reaction mixture.

Representing the DPPH radical by $\mathrm{Z}$ and the donor molecule by $\mathrm{AH}$, the primary reaction is

\section{$\mathrm{Z}+\mathrm{AH}=\mathrm{ZH}+\mathrm{A}(1)$}

Where $\mathrm{ZH}$ is the reduced form and $\mathrm{A}$ is free radical produced in this first step. The free radical obtained will then undergo further reactions which controls the overall stoichiometry, that is, the number of molecules of DPPH reduced (decolorized) by one molecule of the reductant.

The reaction (1) is therefore intended to represent the reactions taking place in an oxidizing system, such as the autoxidation of a lipid or other unsaturated substance. The DPPH molecule $\mathrm{Z}$ represents the free radicals formed in the system whose activity is to be suppressed by the substance $\mathrm{AH}$.

The DPPH method stated here was introduced by Marsden Blois, working at Stanford University, about half a century back [5]. He used the thiol-containing amino acid cysteine as his model antioxidant.

Representing the DPPH radical by $\mathrm{Z}$ and the cysteine molecule by $\mathrm{RSH}$, the initial reaction is then

$\mathrm{Z}+\mathrm{RSH}=\mathrm{ZH}+\mathrm{RS}(2)$ 
The free radical RS reacts with another molecule of the same kind that was produced by a parallel reaction to (2).

\section{$\mathrm{RS}+\mathrm{RS}=\mathrm{RS} \mathrm{SR}(3)$}

The reaction here results in the reduction of two molecules of DPPH by two molecules of cysteine, that is, a 1:1 stoichiometry. In another case, if the molecule has two adjacent sites for hydrogen abstraction connected internally, as like ascorbic acid (Vitamin C), then there may be a further hydrogen abstraction reaction after the first one:

\section{$\mathrm{HO} \mathrm{OHHO} \mathrm{O} \cdot$}<smiles>[AlH2]</smiles>

$$
\mathrm{Z} \bullet+\mathrm{R}-\mathrm{C}=\mathrm{C}-\mathrm{R}^{\prime}=\mathrm{ZH}+\mathrm{R}-\mathrm{C}=\mathrm{C}-\mathrm{R}^{\prime}[4]
$$

$\mathrm{HO}$ O• O O

| | || ||

$$
\mathrm{Z} \bullet+\mathrm{R}-\mathrm{C}=\mathrm{C}-\mathrm{R}^{\prime}=\mathrm{ZH}+\mathrm{R}-\mathrm{C}-\mathrm{C}-\mathrm{R}^{\prime}[5]
$$

This leads to a 2:1 stoichiometry, that is, two molecules of DPPH reduced by one molecule of ascorbic acid. Another example is the reaction of DPPH with hydroquinone (1,4 dihydoxybenzene) that produces quinone (1,4-benzoquinone) by a similar two-step mechanism.

The other compounds stated in the paper to be actively participating in this reaction are glutathione, aromatic amines (such as p-phenylene diamine and p-aminophenol), and a-tocopherol (Vitamin E-2:1 stoichiometry) and polyhydroxy aromatic compounds (such as hydroquinone and pyrogallol), whereas monohydric phenols (such as tyrosine), simple sugars (such as glucose), purines and pyrimidines do not react at all. Proteins get precipitated if subjected to this reaction. It was also noted that "inorganic ions in lower valence states may of course interfere and must be eliminated or determined separately" which presumably applies most importantly to ferrous iron [5].

In the original paper, the presented "typical calibration curve" seems to be slightly different from the original experimental data, since the absorbance values (there called by the previous name, "optical density") are round number values (0.6 down to 0.2$)$, which have been calculated evidently. Even the graph was not extended for the line to meet the axis, as would be expected to give the end-point for the titration. The end-point would correspond to $2.3 \times 10^{-7}$ moles (230 nanomoles) of this substrate (cysteine hydrochloride) if the line was extended to meet the $\mathrm{x}$-axis. The titration if continued beyond the end point is shown in idealized form in Figure 1. Any residual yellow color from the reduced form, or of any absorbance contribution from the added sample itself were not accounted for in this graph.

It is clear that the stated method is a constant-volume colorimetric titration, with complications being a slow reaction process (with mixtures to be allowed to stand for 30 minutes before the absorbance measurement).

The original Blois method has been followed by several recent users $[6,7]$. The relatively newer method of Brand-Williams et al. has been used by some others as a reference [8-11]. This more recent work indicates that the method suggested by Blois is somewhat over simplified, and that because of the complexity of the reactions that follow the initial one (Equation 1), the overall stoichiometry need not necessarily be a whole number (integer) such as 1 or 2 . Furthermore, the initial step (Equation 1) may be reversible, which can be demonstrated by adding the reduced form $\mathrm{ZH}$ at the end of the reaction [12]. Nevertheless, the Blois picture remains a useful one, and the original paper should be read by anyone proposing to use the DPPH method.

Brand-Williams et al. has introduced the parameter "Efficient concentration" or $\mathrm{EC}_{50}$ value (otherwise called the $\mathrm{IC}_{50}$ value) recently to interpret the results of DPPH method $[8,12]$. This is defined as the concentration of substrate that causes $50 \%$ loss of the DPPH activity (color). $\mathrm{EC}_{50}$ parameter has been used subsequently by several groups of users for presenting their results [6,10,13-16].

In practice, it is the " $\mathrm{EC}_{100}$ " value that we are concerned with, which corresponds to the endpoint of the titration. It should be noted that in all these cases, any residual (yellow) color from the reduced form or any non-specific absorbance from the sample has to be taken into account in defining the "endpoint" of the titration, or the " $50 \%$ " point.

Another drawback of the $\mathrm{EC}_{50}$ parameter is that the higher the antioxidant activity, the lower is the value of $\mathrm{EC}_{50}$. This is a disadvantage particularly when results are presented graphically as a bar chart [16] even if the same data is available in numerical form [15].

Herbal based cosmetics are rapidly becoming popular in recent years as an alternative to the synthetic cosmetics. Several polyherbal formulations, which are combinations of different fruit juices/extracts, were traditionally used for the treatment of various skin diseases. Antioxidants being capable of protecting the skin from oxidative damages are included in polyherbal formulations. For developing a satisfactory herbal based cosmetic formulation, there is a need to evaluate the formulation for desired properties such as antioxidant and anti-inflammatory activity. The final polyherbal formulations containing different plants, fruits /extracts must be tested again in the formulation form [17] to determine their efficacy. Hence, a simple and sensitive analytical method is required for evaluating the antioxidant activity as a means of polyherbal formulations. 1,1-diphenyl-2picrylhydrazyl (DPPH) is a stable free radical is used for the evaluation of the general radical scavenging capabilities of various antioxidants [18]. DPPH with an odd electron delocalized over the molecule shows a strong absorption band at $517 \mathrm{~nm}$ in methanol. The scavenging of free radical by antioxidants is achieved by donating Hydrogen to form the stable DPPH-H molecule. The absorbance then decreases because of color change from purple to yellow due to the said reason [19]. The spectrophotometric estimation of DPPH is simple but is not applicable to colored foods due to interference by pigments [20]. Also, the DPPH spectrophotometric method of evaluation may not be of much use to judge the antioxidant activity, as it is not capable to indicate the antioxidant activity of drugs such as nimesulide, dapsone and acetylsalicylic acid etc. [20-22]. Few workers developed DPPH-HPLC method and compared the antioxidant activities of known standard antioxidants and commercial beverages with that of spectrophotometric method. The applicability of HPLC method was extended to determine the antioxidant activity of crude plant extracts/ fruit juice and drugs $[21,23,24]$.

The objective of the present study is to develop, standardize and compare the DPPH-HPLC method with that of spectrophotometric method using known antioxidants, and to evaluate its application to determine the antioxidant activity of selected berry fruit juice freeze dry powder as a means of rapid screening methodology. 
Citation: Kumara P, Sunil K, Arun Kumar B (2018) Determination of DPPH Free Radical Scavenging Activity by RP-HPLC, Rapid Sensitive Method for the Screening of Berry Fruit Juice Freeze Dried Extract. Nat Prod Chem Res 6: 341. doi:10.4172/2329-6836.1000341

Page 3 of 7

\section{Materials and Methods for HPLC}

\section{Materials}

DPPH (90\%) and L-Ascorbic acid were obtained from sigma Aldrich. Mango, Pomegranate, Sweet lemon, Jamun, Acai berry, Goji berry, Black berry and Maqui berry fruit juice freeze dry powders were produced inhouse. HPLC grade Methanol was procured from Finar chemicals and HPLC grade water was produced in house from Elga water purifier.

\section{Sample preparation}

The DPPH and L-Ascorbic acid standard antioxidants were soluble in methanol. Fresh DPPH stock solution (200 millimoles) was prepared prior to the analysis. The stock solutions of ascorbic acid were prepared in methanol at a concentration of 100 micro moles and stored at $25^{\circ} \mathrm{C}$. Samples were prepared by weighing accurately $1.0 \mathrm{gm}$ of fruit juice freeze dry powder in $250 \mathrm{ml}$ round bottom flask and 100 $\mathrm{ml}$ methanol was added. The flask was refluxed on water bath at $80 \pm$ $5^{\circ} \mathrm{C}$ for 30 minutes, cooled to room temperature and then transferred to $100 \mathrm{ml}$ volumetric flask. A portion of the sample was filtered through $0.45 \mu$ Nylon syringe filter prior to HPLC injection.

\section{Spectrophotometry analysis}

Preparation of DPPH: The DPPH and L-Ascorbic acid standard antioxidants were soluble in ethanol. Fresh DPPH stock solution $(0.2$ $\mathrm{mg} / \mathrm{ml}$ ) was prepared on each day of analysis.

Preparation of ascorbic acid: The stock solutions of ascorbic acid were prepared in ethanol at a concentration of $0.1 \mathrm{mg} / \mathrm{ml}$ and stored at $25^{\circ} \mathrm{C}$.

Sample preparation: Accurately $1.0 \mathrm{gm}$ of fruit juice freeze dry powder was weighed into a $250 \mathrm{ml}$ round bottom flask and added 100 $\mathrm{ml}$ methanol, refluxed on water bath $80 \pm 5^{\circ} \mathrm{C}$ for 30 minutes, cooled to room temperature and transferred to a $100 \mathrm{ml}$ volumetric flask. A portion of the sample was filtered through $0.45 \mu$ Nylon syringe filter prior to HPLC injection.

Procedure-standard ascorbic acid: 9 separate $5 \mathrm{~mL}$ volumetric flasks were taken and aliquots of $0.2 \mathrm{ml}, 0.4 \mathrm{ml}, 0.6 \mathrm{ml}, 0.8 \mathrm{ml}, 1.0 \mathrm{ml}, 1.2 \mathrm{ml}$, $1.6 \mathrm{ml}, 1.8 \mathrm{ml}$ and $2.0 \mathrm{ml}$ of $0.1 \mathrm{mg} / \mathrm{ml}$ solution of ascorbic acid standard (antioxidant) were added respectively to separate volumetric flasks. $0.5 \mathrm{ml}$ of $0.2 \mathrm{mg} / \mathrm{ml}$ solution of DPPH was added to each of the mentioned 9 volumetric flasks. Volume was made up to the mark with ethanol, and the flasks were shaken vigorously and allowed to stand at room temperature, protected from light for 30 minutes. Absorbance was measured immediately at $520 \mathrm{~nm}$ by UV spectrophotometer and experiment was done in triplicate. The $\mathrm{IC}_{50}$ value of the standard, which is the concentration of the standard required to inhibit $50 \%$ of the DPPH free radical was calculated using log dose inhibition curve. Lower absorbance of the reaction mixture indicated higher free radical activity. The percentage of DPPH scavenging effect was calculated by following equation.

DPPH scavenging effect (\%)/\% Inhibition $=A_{0}-A_{1} / A_{0} \times 100$

Where $\mathrm{A}_{0}=$ The absorbance of control.

$\mathrm{A}_{1}=$ The absorbance of standard.

Procedure-berry fruit juice freeze dry powder: 9 separate $5 \mathrm{~mL}$ volumetric flasks were taken and aliquots of $0.1 \mathrm{ml}, 0.5 \mathrm{ml}, 1.0 \mathrm{ml}, 1.5$ $\mathrm{ml}, 2.0 \mathrm{ml}, 2.5 \mathrm{ml}, 3.0 \mathrm{ml}, 4.0 \mathrm{ml}$ and $4.5 \mathrm{ml}$ of $1.0 \%$ of sample were added respectively to separate volumetric flasks. $0.5 \mathrm{ml}$ of $0.2 \mathrm{mg} / \mathrm{ml}$ of $\mathrm{DPPH}$ was added to each of the mentioned 9 volumetric flasks. Volume was made up to the mark with ethanol, the flasks was shaken vigorously and allowed stand at room temperature, protected from light for 30 minutes. Absorbance was measured immediately at $520 \mathrm{~nm}$ by using UV spectrophotometer and experiment was done in triplicate. The $\mathrm{IC}_{50}$ value of the standard, which is the concentration of the standard required to inhibit $50 \%$ of the DPPH free radical was calculated using log dose inhibition curve. Lower absorbance of the reaction mixture indicated higher free radical activity. The percentage of DPPH scavenging effect was calculated by following equation.

DPPH scavenging effect (\%)/\% Inhibition $=A_{0}-A_{1} / A_{0} \times 100$

Where $\mathrm{A}_{0}=$ The absorbance of control.

$\mathrm{A}_{1}=$ The absorbance of standard.

\section{HPLC analysis}

Chemical/Reagents details: HPLC grade Methanol.

Reference standard: Ascorbic acid (Sigma Aldrich).

Glassware's details: $100 \mathrm{ml}$ and $5 \mathrm{ml}$ volumetric flasks, $10 \mu \mathrm{l}$, to 1000 $\mu \mathrm{l}$ Micro pipettes.

\section{Apparatus:}

Instrument: HPLC-LC-2030C 3D (Shimadzu-Prominence-I) or any other equivalent.

\section{Chromatographic conditions:}

Column: C18 (Phenomenex Luna-C18 Column)

Length: $250 \mathrm{~mm}$

Diameter id: $4.6 \mathrm{~mm}$

Column oven temperature: $25^{\circ} \mathrm{C}$

Detector: PDA

Wave length: $517 \mathrm{~nm}$

Mobile phase (A:B): Purified Water : Methanol (20:80)

Injection volume: $20 \mu \mathrm{l}$

Flow rate: $1 \mathrm{ml} /$ minute

Cooler temperature: $15^{\circ} \mathrm{C}$

Purge time: 10 Minute

Diluent: Methanol (HPLC grade or any equivalent).

Retention time: 7.23 Minutes

Total run time: 12.0 Minutes.

Preparation of DPPH: The DPPH and L-Ascorbic acid standard antioxidants were soluble in ethanol. Fresh DPPH stock solution (200 micro moles) was prepared on each day of analysis.

Preparation of ascorbic acid: The stock solution of ascorbic acid was prepared in ethanol at a concentration of 100 micro moles and stored at $25^{\circ} \mathrm{C}$.

Sample preparation: Accurately $1.0 \mathrm{gm}$ of fruit juice freeze dry powder was weighed in to $250 \mathrm{ml}$ round bottom flask and $100 \mathrm{ml}$ methanol was added, refluxed on water bath at $80 \pm 5^{\circ} \mathrm{C}$ for 30 
Citation: Kumara P, Sunil K, Arun Kumar B (2018) Determination of DPPH Free Radical Scavenging Activity by RP-HPLC, Rapid Sensitive Method for the Screening of Berry Fruit Juice Freeze Dried Extract. Nat Prod Chem Res 6: 341. doi:10.4172/2329-6836.1000341

Page 4 of 7

minutes, cooled to room temperature and transferred to a $100 \mathrm{ml}$ volumetric flask. A portion of the sample was filtered through $0.45 \mu$ Nylon syringe filter prior to HPLC injection.

Procedure-standard ascorbic acid: 9 separate $5 \mathrm{~mL}$ volumetric flasks were taken and aliquots of $100 \mu \mathrm{l}, 200 \mu \mathrm{l}, 300 \mu \mathrm{l}, 400 \mu \mathrm{l}, 500 \mu \mathrm{l}, 600 \mu \mathrm{l}$, $700 \mu \mathrm{l}, 800 \mu \mathrm{l}, 900 \mu \mathrm{l}$, and $1000 \mu \mathrm{l}$ of 100 micromoles solution of ascorbic acid were added respectively to separate volumetric flasks. $1000 \mu \mathrm{l}$ of 200 micromoles of DPPH solution was added to each of the 9 volumetric flasks and the volume was made up to the mark with ethanol. The flasks were shaken vigorously and allowed to stand at room temperature, protected from light for 30 minutes. A portion of the sample was filtered through $0.2 \mu$ Nylon syringe filter prior to HPLC injection.

System suitability procedure: Injected the diluent as blank till a stable baseline was achieved. Injected the standard and again injected the blank to check the carryover.

Standard was injected 6 times and the \% RSD for standard area was checked.

Relative standard deviation (\%RSD): NMT 5.0\%

Theoretical plates : NLT 2000

Tailing factor: NMT 2.0

Sample analysis was continued once the stated system suitability parameters were achieved.

Procedure for standard analysis: Standard was injected in triplicate into the HPLC. After completion of the analysis, standard peaks were integrated and the average standard area of 3 injections was calculated and considered for calculation. The $\mathrm{IC}_{50}$ value of the standard, which is the concentration of the standard required to inhibit $50 \%$ of the DPPH free radical was calculated using log dose inhibition curve. Lower absorbance of the reaction mixture indicated higher free radical activity. The percentage of DPPH scavenging effect was calculated by following equation.

DPPH scavenging effect (\%)/\% Inhibition $=A_{0}-A_{1} / A_{0} \times 100$

Where $\mathrm{A}_{0}=$ The absorbance of control.

$\mathrm{A}_{1}=$ The absorbance of standard.

Procedure-berry fruit juice freeze dry powder: 9 separate $5 \mathrm{~mL}$ volumetric flasks were taken and aliquots of $25 \mu \mathrm{l}, 50 \mu \mathrm{l}, 75 \mu \mathrm{l}, 100 \mu \mathrm{l}$, $125 \mu \mathrm{l}, 150 \mu, 175 \mu \mathrm{l}, 200 \mu \mathrm{l}, 225 \mu \mathrm{l}$ and $250 \mu \mathrm{l}$ of $1.0 \%$ of sample were added respectively to separate volumetric flasks. $250 \mu \mathrm{l}$ of 200 micromoles of DPPH solution was added to each of the 9 volumetric flasks and the volume was made up to the mark with ethanol. The flasks were shaken vigorously and allowed to stand at room temperature, protected from light for 30 minutes. A portion of the sample was filtered through $0.2 \mu$ Nylon syringe filter prior to HPLC injection.

Immediately the sample was injected in triplicate into the HPLC. After completion of the analysis, sample peaks were integrated and the average sample area of 3 injections was calculated and considered for calculation. The $\mathrm{IC}_{50}$ value of the sample, which is the concentration of the sample required to inhibit $50 \%$ of the DPPH free radical was calculated using log dose inhibition curve. Lower absorbance of the reaction mixture indicated higher free radical activity. The percentage of DPPH scavenging effect was calculated by following equation.

DPPH scavenging effect (\%)/\% Inhibition $=A_{0}-A_{1} / A_{0} \times 100$
Where $\mathrm{A}_{0}=$ The absorbance of control.

$\mathrm{A}_{1}=$ The absorbance of sample.

\section{Results}

\section{Optimization of mobile phase}

As DPPH was soluble in methanol, it was taken up as organic phase. HPLC mobile phase was extensively optimized to achieve good peak shape of DPPH. With the optimized mobile phase ratio of 80:20 :: Methanol:Water the RT of DPPH was found to be at $7.23 \mathrm{~min}$. The peak was well separated with no interferences and acceptable tailing (NMT 2.0) as shown in Figure 1a (DPPH final concentration 200 micromoles). The method was specific for DPPH with no interferences and acceptable tailing (NMT 2.0) and theoretical plates (NLT 2000) as shown in Figure $1 \mathrm{~b}$ (Ascorbic acid final concentration 100 micromoles). Total run time of 12 min was selected to flush out any sample matrices if present and to avoid carryover to the next runs.

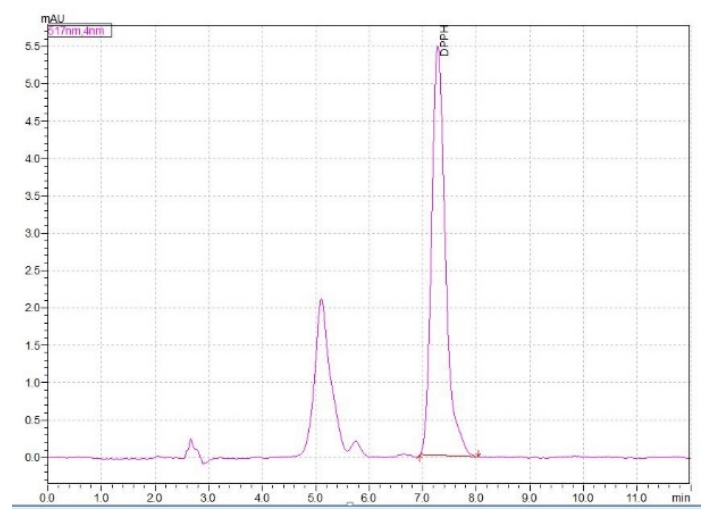

Figure 1a: Optimized mobile phase of methanol:water.

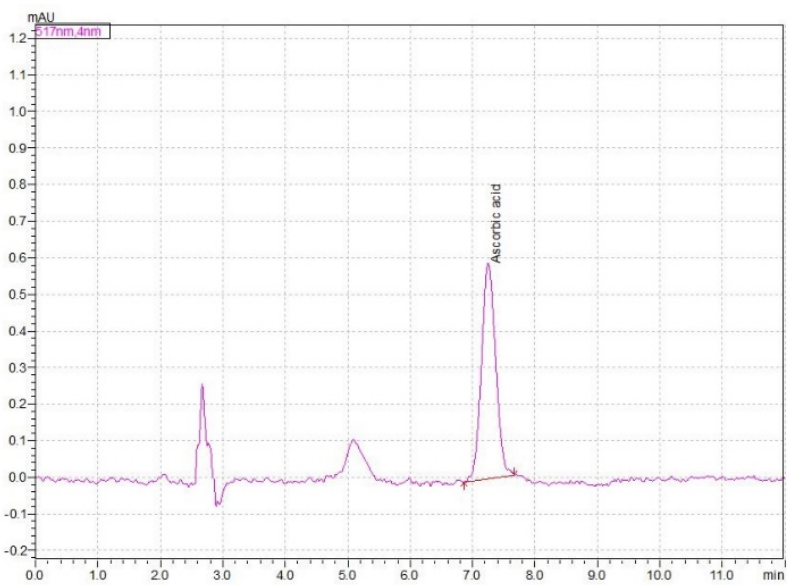

Figure 1b: Acceptable tailing (NMT 2.0) and Theoretical plates (NLT 2000). 
Citation: Kumara P, Sunil K, Arun Kumar B (2018) Determination of DPPH Free Radical Scavenging Activity by RP-HPLC, Rapid Sensitive Method for the Screening of Berry Fruit Juice Freeze Dried Extract. Nat Prod Chem Res 6: 341. doi:10.4172/2329-6836.1000341

Page 5 of 7

\section{Repeatability and reproducibility}

The repeatability and reproducibility of the analytical method was confirmed from the peak area and retention times of the DPPH blank and ascorbic acid solution. The results as listed in Table 1, indicated good repeatability and precision with acceptable R.S.D $(<2 \%)$.

\begin{tabular}{|l|l|l|}
\hline S.No & DPPH & Ascorbic acid \\
\hline 1 & 4835 & 9315 \\
\hline 2 & 4922 & 8883 \\
\hline 3 & 5095 & 9234 \\
\hline 4 & 5001 & 9158 \\
\hline 5 & 5067 & 8925 \\
\hline 6 & 5042 & 9193 \\
\hline Avg & 4993.66 & 9118.00 \\
\hline SDEV & 98.33 & 174.33 \\
\hline$\%$ RSD & 1.96 & 1.91 \\
\hline
\end{tabular}

\begin{tabular}{|l|l|l|}
\hline Tailing factor & 1.057 & 1.105 \\
\hline Theoretical plates & 30,042 & 29,990 \\
\hline
\end{tabular}

Table 1: Repeatability and reproducibility of the peak area of DPPH blank and ascorbic acid solution ( $\mathrm{n}=6)$ by HPLC.

\section{Linearity graphs of standard antioxidants (spectrophotometry v/s HPLC)}

The linearity graphs of all standard antioxidants were constructed by taking the mean value of the triplicate analysis. The linearity of ascorbic acid by spectrophotometry was found to be in the concentration range of $0.2 \mathrm{ml}$ to $2.0 \mathrm{ml}$ (correlation coefficient, $\mathrm{r}^{2}=0.998$ ) Figure $2 \mathrm{a}$, and The linearity of ascorbic acid by HPLC was found to be in the concentration range of $25 \mu \mathrm{l}$ to $250 \mu \mathrm{l}$ (correlation coefficient, $r^{2}=0.989$ ) Figure $2 b$, suggesting that ascorbic acid can be used as standard for comparison of DPPH free radical scavenging activity (Figure $1 \mathrm{~b}$ ). Linear regression equations for all other standard antioxidants also indicated good correlation in the linearity range of 25 $\mu \mathrm{l}$ to $250 \mu \mathrm{l}$ (Table 2).

\begin{tabular}{|c|c|c|c|c|}
\hline \multirow{2}{*}{ S. No } & \multicolumn{2}{|l|}{ Spectrophotometry } & \multicolumn{2}{|l|}{ HPLC } \\
\hline & Concentration $\mathrm{mg} / \mathrm{ml}$ & Absorbance & Concentration $\mu \mathrm{l}$ & Absorbance \\
\hline 1 & 2 & 0.007 & 0.1 & 766.000 \\
\hline 2 & 1.8 & 0.008 & 2.0 & 1817.000 \\
\hline 3 & 1.6 & 0.008 & 3.0 & 2268.000 \\
\hline 4 & 1.4 & 0.009 & 4.0 & 2359.000 \\
\hline 5 & 1.2 & 0.009 & 5.0 & 5060.000 \\
\hline 6 & 1 & 0.01 & 6.0 & 6090.000 \\
\hline 7 & 0.8 & 0.012 & 7.0 & 6597.000 \\
\hline 8 & 0.6 & 0.05 & 8.0 & 7629.000 \\
\hline 9 & 0.4 & 0.094 & 9.0 & 8191.000 \\
\hline 10 & 0.2 & 0.138 & 10.0 & 9408.000 \\
\hline
\end{tabular}

Table 2: Linear regression equations for all other standard antioxidants.

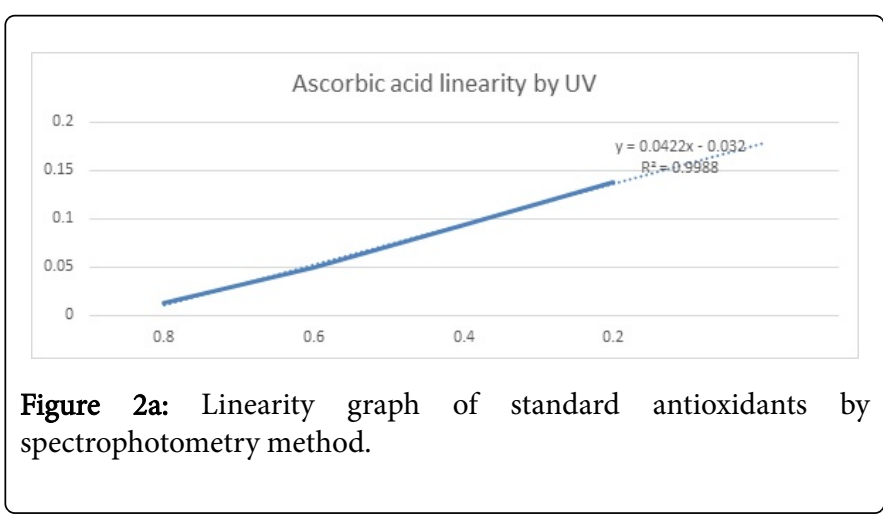

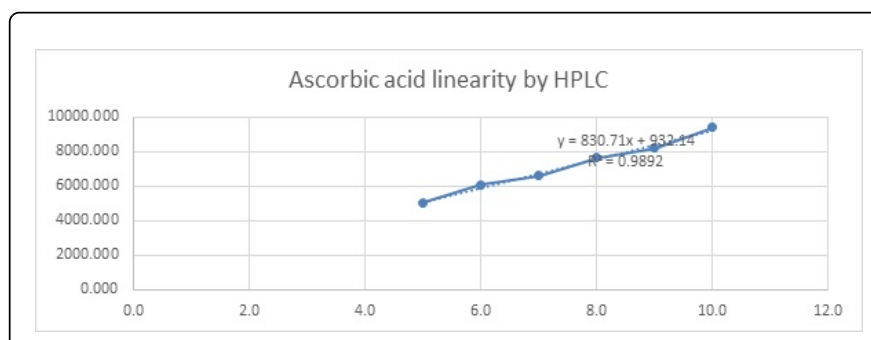

Figure 2b: Linearity graph of standard antioxidants by HPLC method. 
Page 6 of 7

\section{Determination of $\mathrm{IC}_{50}$ values}

The $50 \%$ radical scavenging activity $\left(\mathrm{IC}_{50}\right)$ of the standard antioxidants and Berry fruit juice freeze dry powder is given in Table 3. Based on the $\mathrm{IC}_{50}$ values calculated from the linearity curves of various antioxidants, each mole of ascorbic acid, trapped approximately 100 micromoles and 200 micromoles of $\mathrm{DPPH}$, respectively. Other investigators reported similar results for ascorbic acid [20,25]. The $\mathrm{IC}_{50}$ values for ascorbic acid found by the HPLC method correlated well with that of spectrophotometry estimation.

\begin{tabular}{|l|l|l|l|}
\hline \multirow{2}{*}{ S.No } & Compound Name & \multicolumn{2}{l|}{ IC concentration determined by } \\
\cline { 3 - 4 } & & Spectrophotometry & HPLC \\
\hline 1 & Ascorbic acid & 41.3 & 44.3 \\
\hline 2 & Mango fruit juice freeze dry powder & 88.0 & 29.2 \\
\hline 3 & Pomegranate fruit juice freeze dry powder & 49.3 & 47.7 \\
\hline 4 & Sweet lemon fruit juice freeze dry powder & 122.2 & 45.6 \\
\hline 5 & Jamun fruit juice freeze dry powder & 4.7 & -10.5 \\
\hline 6 & Acai berry fruit juice freeze dry powder & 39.1 & 31.0 \\
\hline 7 & Goji berry fruit juice freeze dry powder & 81.2 & 80.2 \\
\hline 8 & Black berry fruit juice freeze dry powder & -7.7 & -38.0 \\
\hline 9 & Macqui berry fruit juice freeze dry powder & -91.8 & -29.1 \\
\hline Each value is mean \pm S.D. of triplicate analysis. & & \\
\hline
\end{tabular}

Table 3: Free radical scavenging activity of antioxidants and Berry fruit juice freeze dry powder.

\section{Application to polyherbal formulations}

The HPLC method was applied for measuring the free radical scavenging activity of berry fruit juice freeze dry powder in contrast to the standard antioxidants, there was significant difference in the $\mathrm{IC}_{50}$ values of berry fruit juice freeze dry powder when determined by both the methods (Table 3). Spectrophotometry estimation showed no free radical scavenging effect for Black berry, Macqui berry, whereas HPLC method discovered $\mathrm{IC}_{50}$ of the same at lower concentrations.

All these berry fruit juice freeze dry powders contain color pigments which will contribute to the observed difference in the determined $\mathrm{IC}_{50}$ values by the spectrophotometry. The said pigments might interfere with the absorbance of DPPH in the colorimetric method. This unwanted interference may hinder the detection of small changes in the DPPH absorbance. Yamaguchi et al. [20] reported similar results for beverages indicating the insensitiveness and non-specific analysis of DPPH by spectrophotometry.

However, the novel HPLC method was specific for DPPH and was based on the reduction in DPPH peak area. The superiority of HPLC method was more evident from the detection of small changes in the $\mathrm{DPPH}$ absorbance reflected by the peak area even in the presence of mixture of berry fruit juice freeze dry powder and colorants.

\section{Conclusion}

The current skin care market is witnessing a huge influx of a variety of berry fruit freeze dry powder for the care and maintenance and skin and other health related disorders. This in turn has increased the demand for rapid standardization and analytical methods to differentiate any batch-to-batch variations and also their efficacies. The age old DPPH spectrophotometric method for evaluation of antioxidant activity is not capable of indicating the exact antioxidant activity of certain fruit freeze dry powder due to the interferences from color pigments of the matrices itself. Hence a simple and sensitive novel HPLC method was developed for screening antioxidant activity of berry fruit juice freeze dry powder. The developed HPLC method was specific for DPPH with an acceptable reproducibility within a short run time allowing for rapid determination of radical scavenging activity of several samples. The $\mathrm{IC}_{50}$ values determined for the standard antioxidants by the HPLC method conforms well to those determined by Spectrophotometry. This HPLC method was successfully applied for the determination of antioxidant activity of berry fruit juice freeze dry powders and can serve as a quality control tool.

\section{References}

1. Abdalla AE, Roozen JP (1999) Effect of plant extracts on the oxidative stability of sunflower oil and emulsion. Food Chemistry 64: 323-329.

2. Sanchez Moreno C (2002) Review: methods used to evaluate the free radical scavenging activity in foods and biological systems. Food Sci Tech Int 8: 121-137.

3. Schwarz K, Bertelsen G, Nissen LR, Gardner PT, Heinonen MI, et al (2001) Investigation of plant extracts for the protection of processed foods against lipid oxidation. Comparison of antioxidant assays based on radical scavenging, lipid oxidation and analysis of the principal antioxidant compounds. Eur Food Res Technol 212: 319-328.

4. Wanjek C (2001) Mixed messages: antioxidants may in some cases do more harm than good. The Washington Post 7.

5. Blois MS (1958) Antioxidant determinations by the use of a stable free radical. Nature 181: 1199-1200.

6. Kim JK, Noh JH, Lee S, Choi JS, Suh H, et al. (2002) The first total synthesis of 2,3,6-tribromo-4,5- dihydroxybenzyl methyl ether (TDB) and its antioxidant activity. Bull Korean Chem Soc 23: 661-662. 
Citation: Kumara P, Sunil K, Arun Kumar B (2018) Determination of DPPH Free Radical Scavenging Activity by RP-HPLC, Rapid Sensitive Method for the Screening of Berry Fruit Juice Freeze Dried Extract. Nat Prod Chem Res 6: 341. doi:10.4172/2329-6836.1000341

Page 7 of 7

7. Zhu QY, Hackman RM, Ensunsa JL, Holt RR, Keen CL (2002) Antioxidative activities of oolong tea. J Agric Food Chem 50: 6929-6934.

8. Brand Williams W, Cuvelier ME, Berset C (1995) Use of a free radical method to evaluate antioxidant activity. LWT-Food Science and Technology 28: 25-30.

9. Gomez Alonso S, Fregapane G, Salvador MD, Gordon MH (2003) Changes in phenolic composition and antioxidant activity of virgin olive oil during frying. J Agric Food Chem 51: 667-672.

10. Lebeau J, Furman C, Bernier JL, Duriez P, Teissier E, et al. (2000) Antioxidant properties of di-tert-butylhydroxylated flavonoids. Free Radic Biol Med 29: 900-912.

11. Yepez B, Espinosa M, Lopez S, Bolanos G (2002) Producing antioxidant fractions from herbaceous matrices by supercritical fluid extraction. Fluid Phase Equil 197: 879-884.

12. Bondet V, Brand Williams W, Berset C (1997) Kinetics and mechanisms of antioxidant activity using the DPPH• free radical method. LWT-Food Science and Technology 30: 609-615.

13. Leitao GG, Leitao SG, Vilegas W (2002) Quick preparative separation of natural naphthoquinones with antioxidant activity by high-speed counter-current chromatography. Naturforsch 57: 1051-1055.

14. Lu Y, Foo LY (2000) Antioxidant and radical scavenging activities of polyphenols from apple pomace. Food Chemistry 68: 81-85.

15. Sanchez Moreno C, Larrauri JA, Saura Calixto F (1998) New parameter for evaluation of free radical scavenging capacity of polyphenols. 2nd International Electronic Conference on Synthetic Organic Chemistry (ESCOC-2).

16. Sanchez Moreno C, Larrauri JA, Saura Calixto F (1999) Free radical scavenging capacity and inhibition of lipid oxidation of wines, grape juices and related polyphenolic constituents. Food Res Int 32: 407-412.
17. Subramoniam A, Pushpangadan P (1999) Development of phytomedicines for liver disease. Indian Journal of Pharmacology 31: 166.

18. Williams WB, Cuvelier ME, Berset C (1995) Lebebsmittel Wissen Techn. Food Sci Technol 28: 25-30.

19. Arouma O, Halliwell B, Williamson G (1997) Antioxidant Methodology. AOCS Press, IL, USA, pp:173-204.

20. Yamaguchi T, Takamura H, Matoba T, Terao J (1998) HPLC method for evaluation of the free radical-scavenging activity of foods by using 1, 1diphenyl-2-picrylhydrazyl. Biosci Biotech Biochem 62: 1201-1204.

21. Karunakar N, Prabhakar MC, Krishna D (2003) Determination of antioxidant activity of some drugs using high-pressure liquid chromatography. Arzneim Forsch Drug Res 53: 254-259.

22. Burmistrov SO, Oparina TI, Prokopenko VM (1997) Antioxidant activity of the blood serum in pregnant and nonpregnant women: comparison of various detection methods. Klin Lab Diag 11: 14-18.

23. Dapkevicius A, van Beek TA, Niederländer HA (2001) Evaluation and comparison of two improved techniques for the on-line detection of antioxidants in liquid chromatography eluates. Journal of Chromatography A 912: 73-82.

24. Krishnaiah P, Reddy VN, Venkataramana G, Ravinder K, Srinivasulu M et al. (2004) New Lamellarin Alkaloids from the Indian Ascidian Didemnum o bscurum and their antioxidant properties. Journal of Natural Products 67: 1168-1171.

25. Koleva II, Niederländer HA, Van Beek TA (2000) An on-line HPLC method for detection of radical scavenging compounds in complex mixtures. Analytical Chemistry 72: 2323-2328. 